\title{
Análise dos casos suspeitos da Covid-19 nos pacientes em programa de diálise ambulatorial
}

\author{
Study of suspicious cases of Covid-19 in patients in an outpatient dialysis program \\ Estudio de casos sospechosos de Covid-19 en pacientes en un programa de diálisis ambulatoria \\ Natália Melazo Mendonça Machado ${ }^{1 *}$, Vinícius Cortês Viana, Paula Gabriella Costa Da Penha1.
}

\section{RESUMO}

Objetivo: Analisar os casos suspeitos da Covid-19 em pacientes em um programa de tratamento de diálise ambulatorial do setor de nefrologia em um hospital na região metropolitana do estado do Pará. Métodos: Foram avaliados 36 pacientes considerados suspeitos de infecção pelo Covid-19 através de dados extraídos da tabela elaborada para controle interno dos casos. Resultados: Em quase $60 \%$ dos pacientes o resultado do RT-PCR para Covid-19 foi positivo. Vinte pacientes eram do sexo feminino, com faixa etária predominante acima dos 70 anos. A dispneia e coriza foram os sinais e sintomas mais frequentes encontrados nos pacientes positivos e, dentre estes, $70 \%$ apresentaram alterações tomográficas de tórax. A maioria dos pacientes necessitou de internação hospitalar para o tratamento e evoluíram com melhora clínica seguida de alta. Conclusão: A prevalência de Covid foi alta no grupo estudado, sendo a idade avançada um possível fator de risco. Apesar de ser uma doença sistêmica, o acometimento respiratório é uma das principais características observadas com a presença de dispneia e coriza, além de alterações tomográficas. A necessidade de tratamento intra-hospitalar do grupo reforça sua susceptibilidade a quadros mais graves do enfermo.

Palavras-chave: Hemodiálise, COVID-19, Falência renal crônica.

\begin{abstract}
Objective: To analyze suspected cases of Covid-19 in patients in an outpatient dialysis treatment program in the nephrology sector of a hospital in the metropolitan region of the state of Pará. Methods: 36 patients considered suspected of infection by Covid-19 were evaluated through data extracted from the table prepared for internal control of cases. Results: In almost $60 \%$ of patients, the RT-PCR result for Covid-19 was positive. Twenty patients were female, with a predominant age group above 70 years. Dyspnea and coryza were the most frequent signs and symptoms found in positive patients and, among these, $70 \%$ had CT scans of the chest. Most patients required hospitalization for treatment and progressed with clinical improvement followed by discharge. Conclusion: The prevalence of Covid was high in the studied group, with advanced age being a possible risk factor. Despite being a systemic disease, respiratory involvement is one of the main characteristics observed with the presence of dyspnea and coryza, in addition to tomographic changes. The group's need for in-hospital treatment reinforces its susceptibility to more severe conditions.
\end{abstract}

Key words: Hemodialysis, COVID-19, Kidney failure chronic.

\section{RESUMEN}

Objetivo: Analizar casos sospechosos de Covid-19 en pacientes en programa de tratamiento ambulatorio de diálisis en el sector de nefrología de un hospital de la región metropolitana del estado de Pará. Métodos: se evaluaron 36 pacientes considerados sospechosos de infección por Covid -19 a través de datos extraídos del cuadro elaborado para el control interno de casos. Resultados: En casi el $60 \%$ de los pacientes, el resultado de RT-PCR para Covid-19 fue positivo. Veinte pacientes eran del sexo femenino, con un grupo de edad predominante por encima de los 70 años. La disnea y la coriza fueron los signos y síntomas más frecuentes encontrados en los pacientes positivos y, de estos, el 70\% tenían TAC de tórax. La mayoría de los pacientes requirieron hospitalización para el tratamiento y evolucionaron con mejoría clínica seguida de alta. Conclusión: La prevalencia de Covid fue alta en el grupo estudiado, siendo la edad avanzada un posible factor de riesgo. A pesar de ser una enfermedad sistémica, la afectación respiratoria es una de las principales

${ }^{1}$ Fundação Hospital de Clínicas Gaspar Vianna, Belém - PA. E-mail: nataliammmachado@hotmail.com

SUBMETIDO EM: 12/2021

ACEITO EM: 12/2021

PUBLICADO EM: 1/2022 
características observadas con la presencia de disnea y coriza, además de alteraciones tomográficas. La necesidad del grupo de tratamiento en el hospital refuerza su susceptibilidad a condiciones más severas.

Palabras clave: Hemodiálisis, COVID-19, Fallo renal crónico.

\section{INTRODUÇÃO}

O vírus Severe Acute Respiratory Syndrome Coronavirus (SARS-CoV) é um agente infeccioso que está presente em nosso mundo há milhares de anos sendo dois dos seus sete subtipos responsáveis por epidemias virulentas nos anos de 2003 na China e na Arábia Saudita em 2012 (FEHR AR, et al., 2015, 2020). Dentre esses subtipos, poucos possuem a capacidade de infectar animais e seres humanos ao mesmo tempo (MINISTÉRIO DA SAÚDE, 2020).

Recentemente, em dezembro do ano de 2019, em Wuhan na China, foi descoberto um novo subtipo de coronavírus conhecido como SARS-CoV-2, capaz de infectar animais e seres humanos (ZHU N, et al., 2020). O mesmo é o responsável pela doença conhecida como Covid-19, possuindo múltiplas propriedades infectocontagiosas ainda desconhecidas e gerando o atual cenário caótico de pandemia (MCINTOSH K, 2020).

Atualmente o quadro clínico ocasionado pelo mesmo é altamente variável entre a população podendo se manifestar de forma assintomática ou até mesmo evoluir para quadros graves com necessidade de suporte ventilatório. A Organização Mundial da Saúde (OMS) estima que em até $80 \%$ da população a infecção pelo vírus irá se manifestar de forma assintomática ou com sintomas leves e $20 \%$ dos quadros necessitarão de internação hospitalar, destes $5 \%$ de ambiente de Unidade de Terapia Intensiva (UTI). Até o momento se mantém desconhecido os fatores que determinam a evolução da doença em cada ser humano (WORLD HEALTH ORGANIZATION, 2020).

Mesmo após vários meses de pandemia decretada, e diversos especialistas do mundo todo empenhados em busca de descobertas e de uma terapêutica eficaz no combate ao SARS-Cov-2, pouco se avançou sobre o enfermo. Sua fisiopatologia, os fatores de risco envolvidos, principais sintomas, métodos diagnósticos e o tratamento mais eficaz ainda permanecem incertos (MINISTÉRIO DA SAÚDE, 2020).

Em países que possuem altos níveis de desenvolvimento econômico, tecnológico e de bom amparo em saúde como nos países da Europa, América do Norte e Ásia, a Covid-19 foi responsável pela morte de milhares de pessoas nos últimos seis meses, inclusive sem assistência médica adequada devido ao aumento exponencial no número de casos na população superlotando os sistemas de saúde. Diante desse panorama, e buscando-se promover um achatamento de curva, demandou-se a necessidade urgente da adoção de medidas de distanciamento e isolamento social, regime de quarentena, uso de equipamentos de proteção individual, além de medidas de higiene constantes visando reduzir a transmissibilidade pessoa a pessoa (BASILE C, et al., 2020).

Segundo dados fornecidos pela OMS até o mês de Outubro de 2020 já foram detectados aproximadamente quarenta e um milhões de casos confirmados no mundo todo, sendo os Estados Unidos um dos países mais acometidos com mais de oito milhões de casos e duzentos e vinte e uma mil mortes. No Brasil o cenário aponta para cinco milhões de pessoas infectadas e cento e cinquenta mil mortos (WORLD HEALTH ORGANIZATION, 2020).

Especialmente para os pacientes portadores de Doença Renal Crônica (DRC) em hemodiálise intermitente o contexto pandêmico é um cenário desafiador. Os múltiplos aspectos envolvidos em sua condição clínica dificultam e até impedem que várias das medidas preventivas recomendadas contra o vírus sejam adotadas, sendo por esse motivo, a condição de base um dos fatores de risco para a contaminação viral. Dentre essas estão a impossibilidade de manter o isolamento social, o uso de transporte comunitário até a unidade de terapia, salas de espera e de tratamento compartilhados, a idade avançada na maioria dos pacientes e a presença de múltiplas comorbidades associadas ao acometimento renal, tornando -os um grupo vulnerável a infecção pelo SARS-CoV-2 (BASILE C, et al., 2020). 
A necessidade da realização do tratamento de forma continuada e semanal trouxe uma série de implicações na rotina dos serviços e clínicas de hemodiálise a serem adotados pelos pacientes, profissionais de saúde, gestores dos centros de diálise e de autoridades sanitárias visando minimizar 0 risco de transmissão do vírus. A Sociedade Brasileira de Nefrologia (SBN) elaborou uma nota técnica denominada de "Recomendações de boas práticas da Sociedade Brasileira de Nefrologia às Unidades de Diálise em relação a Epidemia do novo Coronavírus (COVID-19)" contendo medidas a serem adotadas, dentre elas a intensificação da higienização das mãos com álcool gel 70\% ou lavagem com água e sabão, uso do Equipamento de Proteção Individual (EPI), manutenção do distanciamento social entre os pacientes, triagem e isolamento dos casos suspeitos, paramentação completa da equipe, além da intensificação da limpeza o setor (SOCIEDADE BRASILEIRA DE NEFROLOGIA, 2020).

No cenário da assistência à saúde a SBN formalizou sua recomendação para rastreio e diante dos casos confirmados de Covid-19 as indicações para a descontinuação do isolamento de pacientes e retorno às atividades de profissionais de saúde e colaboradores com suspeita ou confirmação da doença (SOCIEDADE BRASILEIRA DE NEFROLOGIA, 2020).

Tais recomendações foram seguidas nos serviços de hemodiálise do estado do Pará, adotando medidas de precaução e de controle contra a COVID-19, além de promover a capacitação das equipes e a aplicação de protocolos voltados para a assistência (SECRETARIA DE SAÚDE PÚBLICA, 2021).

À vista de todo o contexto supracitado e buscando analisar o perfil dos casos suspeitos nos pacientes dialíticos em um serviço de hemodiálise no estado do Pará, se torna pertinente à execução deste trabalho visando contribuir com o fornecimento de dados para a população e a sociedade científica sobre o Covid19.

\section{MÉTODOS}

O estudo foi do tipo epidemiológico transversal, quantitativo e descritivo dos dados obtidos da tabela de pesquisa. O projeto foi apreciado pelo Comitê de Ética em Pesquisa (CEP) e dado início a coleta de dados após sua aprovação (CAAE: 51003521.5.0000.0016) na data de 27 de setembro de 2021. Houve o cumprimento de toda a legislação que estabelece preceitos norteadores de pesquisas com seres humanos: Declaração de Helsinque, Código de Nuremberg e a resolução 466/12 do CONEP. O estudo foi realizado no Setor de Terapia Renal Substitutiva (STRS) em um hospital na região metropolitana do estado do Pará no período que corresponde de abril a dezembro de 2020.

Os dados foram extraídos da tabela elaborada, durante o período da pandemia, pela equipe médica do STRS, para controle interno dos casos suspeitos, entre a equipe médica e a equipe de enfermagem, nela identificado: sexo, idade, data e os principais sintomas apresentados, alteração radiológica em tomográfica computadorizada de tórax, resultado do exame reação da transcriptase reversa seguida pela reação em cadeia da polimerase (RT-PCR) e desfecho clínico dos pacientes suspeitos para infecção por covid - 19 .

Fizeram parte do estudo pacientes de ambos os sexos, de qualquer raça/etnia, em terapia dialítica inscritos no programa ambulatorial de hemodiálise de um hospital na região metropolitana do estado do Pará, que foram identificados com sintomas e notificados como suspeitos para infeção por Covid-19. Foram excluídos do estudo pacientes suspeitos para infecção por Covid-19 que não faziam parte deste programa de diálise ambulatorial estudado.

Os elementos coletados na amostra analisada foram apurados e registrados em planilha elaborada no software Microsoft $t^{\circledR}$ Office Exce $^{\circledR}$ 2016. A partir desta, houve a realização da Estatística Descritiva com a construção de gráficos e tabelas para apresentação dos resultados e calculadas a média aritmética e desvio padrão.

$\mathrm{Na}$ avaliação dos resultados das variáveis encontradas foi aplicada a estatística analítica através dos Testes G e Qui-Quadrado Aderência para tabelas univariadas e Independência para tabelas bivariadas. O software BioEstat ${ }^{\circledR}$ 5.4. foi utilizado na aplicação das estatísticas descritiva e analítica. O nível de significância 
$\alpha=0,05$ ou $5 \%$ foi disposto, sendo este sinalizado com asterisco $\left(^{*}\right)$, para os valores considerados significantes.

Os riscos desta pesquisa foram relacionados a possibilidade de exposição da identidade dos pacientes envolvidos, sendo minimizado com a não utilização de quaisquer informações como nomes, documentos ou outros dados pessoais. Os benefícios da pesquisa envolveram os próprios pacientes, pesquisadores, o hospital envolvido e a comunidade científica, considerando que, os resultados obtidos proporcionaram um maior conhecimento sobre a infecção pela Covid-19 nesse grupo e a possibilidade de uma melhor abordagem dos pacientes.

\section{RESULTADOS}

A amostra foi composta por 36 pacientes considerados suspeitos. Quanto ao gênero, 20 pertenciam ao sexo feminino e 16 ao masculino, não sendo identificada diferença estatisticamente significante $(p=0.6171)$ nas proporções entre os sexos. Em relação à idade, a maior proporção esteve na faixa etária entre 70 e 79 anos (27.8\%), seguido das faixas etárias entre 60 a 69 anos e 40 a 49 anos (16.7\% cada). Não havendo diferença estatisticamente significante $(p=0.1581)$ entre as faixas etárias presentes (Tabela 1).

Tabela 1 - Perfil epidemiológico dos pacientes, abril a dezembro/2020.

\begin{tabular}{lccc}
\hline \multicolumn{1}{c}{ Variáveis } & Frequência & $\%$ (N=36) & p-valor \\
\hline Sexo & & & \\
\hline Feminino & 20 & $55.6 \%$ & 0.6171 \\
Masculino & 16 & $44.4 \%$ & \\
\hline Faixa etária (anos) & & & \\
\hline < 30 & 2 & $5.6 \%$ & \\
30 a 39 & 3 & $8.3 \%$ & \\
40 a 49 & 6 & $16.7 \%$ & 0.1581 \\
50 a 59 & 4 & $11.1 \%$ & \\
60 a 69 & 6 & $16.7 \%$ & \\
70 a 79 & 10 & $27.8 \%$ & \\
> 80 & 3 & $8.3 \%$ & \\
Sem informação & 2 & $5.6 \%$ & \\
\hline
\end{tabular}

Mín / Média \pm DP / Máx 19 / $60.0 \pm 18.6$ / 91

Legenda: ${ }^{*} T e s t e$ Qui-Quadrado Aderência; ${ }^{* *} T e s t e ~ G$ Aderência; Mín: mínimo; DP: desvio padrão; Máx: máximo. Fonte: Machado NMM, et al., 2021. dados extraídos do Setor de Terapia Renal Substitutiva.

$\mathrm{Na}$ análise do resultado de exames da reação da transcriptase reversa seguida pela reação em cadeia da polimerase (RT-PCR) para Covid-19 realizados na amostra, foi observado uma maior proporção para os resultados positivos (58.8\%), seguido dos negativos (38.2\%) e inconclusivo $(3.0 \%)$, não havendo proporção estatisticamente significante $(p=0.2230)$ após realização de testes estatísticos, conforme demonstrado na Tabela 2. No total, foram realizados 34 testes, restando apenas dois pacientes que não realizaram o exame devido indisponibilidade do mesmo no momento da suspeita diagnóstica.

Tabela 2 - Pacientes segundo o exame de reação da transcriptase reversa seguida pela reação em cadeia da polimerase no período de abril a dezembro/2020.

\begin{tabular}{|c|c|c|c|}
\hline Variável & Frequência & $\%(\mathrm{~N}=36)$ & p-valor \\
\hline Resultado PCR & & $n=34$ & \\
\hline Positivo & 20 & $58.8 \%$ & \\
\hline Negativo & 13 & $38.2 \%$ & 0.2230 \\
\hline Inconclusivo & 1 & $3.0 \%$ & \\
\hline
\end{tabular}

Fonte: Machado NMM, et al., 2021; dados extraídos do Setor de Terapia Renal Substitutiva.

Ao serem avaliadas as proporções dos sintomas em relação aos pacientes com a Covid -19, identificou-se que a dispneia apresentou maior proporção (72.7\%), sendo esta a única cujo resultado estatístico foi 
significante $\left({ }^{*} p<0.0001\right)$, seguido da coriza com $66.7 \%$, dor na garganta $(62.5 \%)$, tosse $(55.0 \%)$, cefaleia $(50.0 \%)$ e febre $(45.0 \%)$, entre outros (Gráfico 1 ).

Gráfico 1: Sintomas apresentados pelos pacientes confirmados positivos para Covid-19.

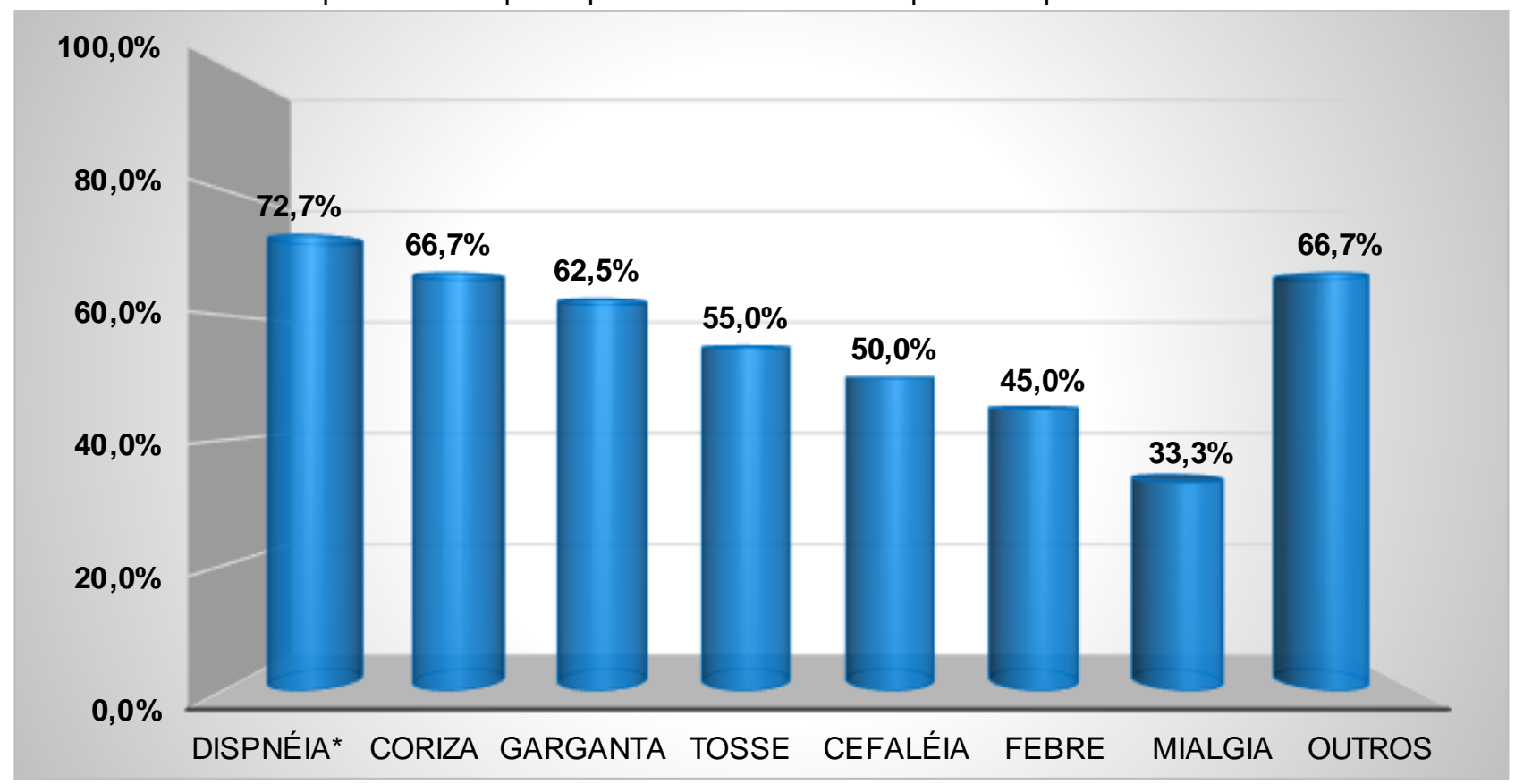

Legenda: *Teste G Aderência;

Fonte: Machado NMM, et al., 2021; dados extraídos do Setor de Terapia Renal Substitutiva.

Na comparação entre a presença ou ausência de alterações tomográficas nos pacientes com o resultado da reação da transcriptase reversa seguida pela reação em cadeia da polimerase (RT-PCR) para Covid-19 positivos, foi encontrada diferença estatisticamente significante ( $\left.{ }^{*} \mathrm{p}=0.0010\right)$, onde a maior proporção de resultados alterados ficou com entre os pacientes positivos (70.0\%) (Gráfico 2).

Gráfico 2 - Resultado da Tomografia de tórax apresentados pelos pacientes com Covid-19, abril a dezembro/2020.

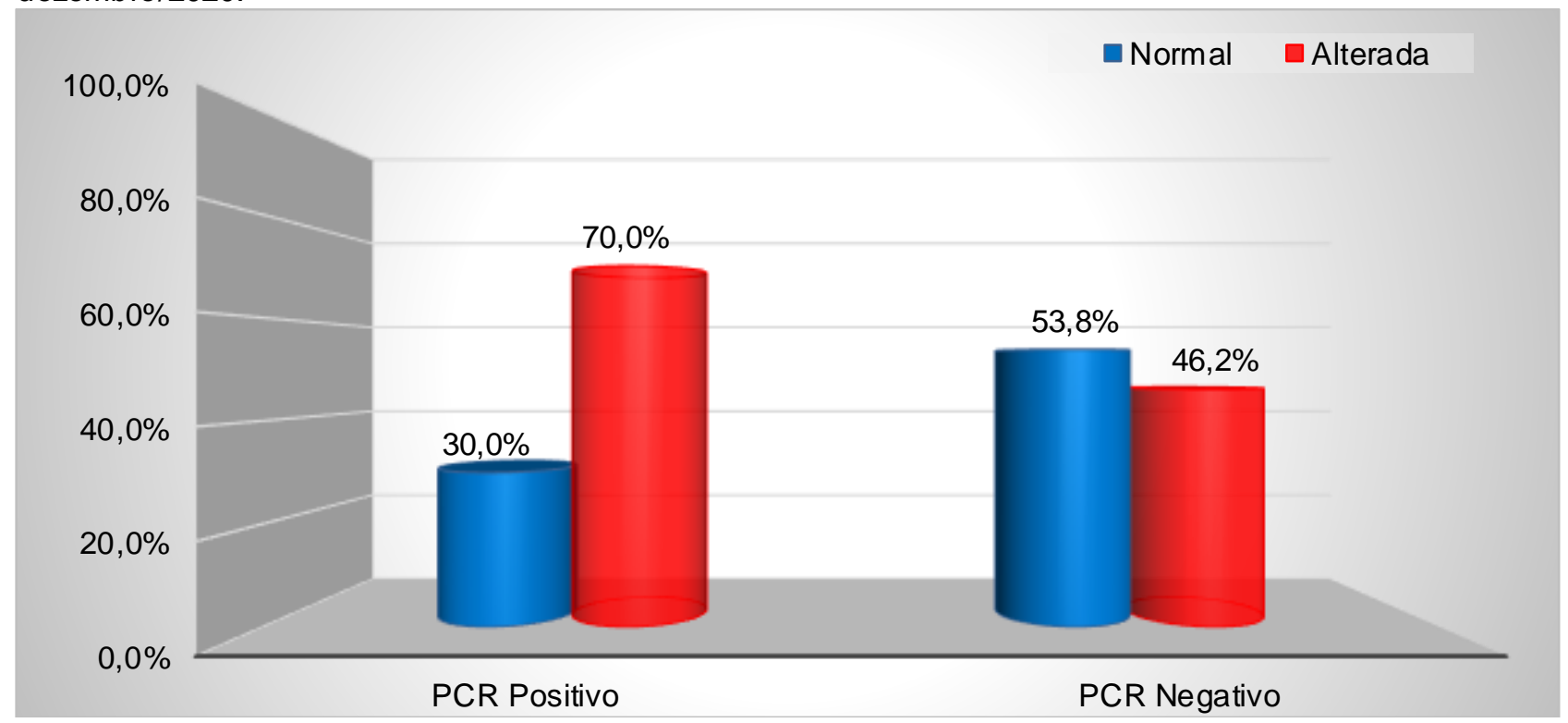

Fonte: Machado NMM, et al., 2021; dados extraídos do Setor de Terapia Renal Substitutiva. 
No quesito desfecho dos atendimentos realizados aos pacientes com resultados com Covid -19 não houve diferença estatisticamente significante $(p=0.8321)$ entre as proporções encontradas. A maioria dos pacientes necessitaram de internação hospitalar para o tratamento e evoluíram com melhora seguida de alta $(43,5 \%)$. $30,4 \%$ necessitaram apenas de tratamento ambulatorial (30.4\%) e cerca de $26.1 \%$ evoluíram a óbito (Tabela 3).

Tabela 3 - Desfecho do atendimento, abril a dezembro/2020.

\begin{tabular}{ccc}
\hline Desfecho do atendimento & Frequência & $\%$ (N=23) \\
\hline Tratamento ambulatorial & 7 & $30.4 \%$ \\
Internação - Alta & 10 & $43,5 \%$ \\
IOT - Óbito & 6 & $26.1 \%$ \\
\hline
\end{tabular}

Legenda: IOT: intubação orotraqueal.

Fonte: Machado NMM, et al., 2022; dados extraídos do Setor de Terapia Renal Substitutiva.

Quanto às comorbidades apresentadas pelos pacientes participantes da pesquisa, observou-se que a maioria, estatisticamente significante $\left({ }^{*} p<0.0001\right)$, apresentava HAS $(72.2 \%)$. Entre as demais comorbidades, foram identificadas também principalmente a Diabetes Mellitus 2 (47.2\%), a cardiopatia $(16.7 \%)$ e a Hepatite B $(8.3 \%)$, entre outras (Tabela 4$)$.

Tabela 4 - Comorbidades apresentados, abril a dezembro/2020.

\begin{tabular}{ccc}
\hline Comorbidades & Frequência & $\%(\mathbf{N}=\mathbf{3 6})$ \\
\hline HAS & 26 & $72.2 \%$ \\
DM 2 & 17 & $47.2 \%$ \\
Cardiopatia & 6 & $16.7 \%$ \\
Hepatite B & 3 & $8.3 \%$ \\
Dislipidemia & 2 & $5.6 \%$ \\
LES & 2 & $5.6 \%$ \\
DPOC & 1 & $2.8 \%$ \\
CA Gástrico & 1 & $2.8 \%$ \\
Cirrose & 1 & $2.8 \%$ \\
Outras & 4 & $11.1 \%$ \\
\hline
\end{tabular}

Legenda: ${ }^{*} \mathrm{p}<0.0001$ Teste G Aderência; HAS: hipertensão arterial sistêmica; DM2: diabetes mellitus do tipo 2; LES: lúpus eritematoso sistêmico; DPOC: doença pulmonar obstrutiva crônica; CA gástrico: câncer gástrico. Fonte: Machado NMM, et al., 2021; dados extraídos do Setor de Terapia Renal Substitutiva.

\section{DISCUSSÃO}

Diante da conjuntura emergencial de uma "nova" doença com prognóstico até então desconhecido pela sociedade médica e científica, e por tratar-se de um subtipo do vírus pouco estudado quanto a fisiopatologia, diagnóstico e tratamento, até o presente momento, os relatos consistentes na literatura são muito escassos. Neste aspecto os pacientes têm sido conduzidos de diferentes formas no mundo todo (INAH MARIA D, et al., 2021).

Quanto ao acometimento deste enfermo nos pacientes renais crônicos dialíticos o cenário é de alto risco. Os mesmos possuem elevada probabilidade de contrair a infecção devido a impossibilidade de realizar isolamento social e a necessidade de exposição a ambientes hospitalares frequentemente para realizar 0 tratamento (NAICKER S, et al., 2020).

Tais ponderações promoveram o surgimento de protocolos nacionais e internacionais relacionados a condução e aos cuidados da Covid-19 nos pacientes renais crônicos nos centros de hemodiálise. Os mesmos são baseados na alta disseminação do vírus e reforçam a necessidade do uso de equipamentos de proteção individuais, suspensão do transporte coletivo, triagem na chegada quanto a sintomas e do isolamento dos casos suspeitos e internação para tratamento dos casos confirmados. Também reiteram a necessid ade das medidas de higiene, limpeza do local entre os turnos, lavagem de mãos, desinfecção e do uso obrigatório de 
máscaras tanto envolvendo toda a equipe de saúde, os pacientes e os acompanhantes (ROMBOLA G, et al., 2020).

As primeiras divulgações científicas que surgiram dos pacientes renais crônicos dialíticos já sobressaltava suas fragilidades, como o relatório sobre a Covid-19 em Wuhan, na China, publicado por Yiqiong MA, et al. (2019), no início da primeira onda, onde já havia indícios que demonstravam o maior risco desse grupo de pacientes (BASILE C, et al., 2020).

No Brasil, o primeiro caso de Covid-19 confirmado ocorreu em fevereiro de 2020 e deu início ao aumento exponencial no número de casos no país, incluindo os pacientes portadores de doença renal crônica em hemodiálise. Em dezembro do mesmo ano, uma revisão sistemática baseada em dados bibliog ráficos da PubMed envolvendo 37.852 pacientes dialíticos no Brasil foi publicada. A mesma apontou o total de 1.291 pacientes dialíticos infectados até aquele momento e as taxas de incidência, mortalidade e fatalidade foram de $341 / 10.000,94 / 10.000$ e $27,7 \%$, respectivamente, reforçando as preocupações quanto à vulnerabilidade deste grupo em meio à pandemia da Covid-19 (INAH MARIA D, et al., 2021).

No presente trabalho, entre a média de 50 pacientes que dialisavam setor, observou-se um acometimento de quase metade desses doentes. 20 no total, que correspondem a 40\% de casos confirmados no STRS. Já em alguns relatórios da literatura divulgados ainda nos meses iniciais do ano de 2020, observou-se o contrário. No centro de hemodiálise do Hospital Renmin da Universidade de Wuhanem em Wuhan, na região metropolitana da França, na região da Brécia, na Itália e no centro de Madrid, na Espanha, e em Toronto, no Canadá demonstraram um menor acometimento percentual, correspondendo a 16,09\%, 3,3\%, 15\%, 11,8\% e $9,2 \%$ respectivamente. Cabe ressaltar que o tempo analisado nas amostras desses estudos comparativos foi em média de 30 a 60 dias, diferentemente do período estabelecido nesse trabalho que foi de nove meses, aumentando os riscos de contaminação ligados a um maior tempo de exposição, possivelmente justificando o maior percentual envolvido (BAYER F, et al., 2021).

Quanto a faixa etária, o resultado observado neste estudo demonstrou maior acometimento entre os 70 e 79 anos de idade, semelhante a maioria dos dados da literatura encontrados. Estudos na França e Itália, observaram a média de 75 e 72 anos respectivamente em suas amostras (ALBERICI F, et al., 2021). Já Estados Unidos e Coréia do Sul ambas apresentaram a idade média de 63 anos e a China apresentou a média de 66 anos de idade (VALERI AM, et al., 2021). Observando-se a idade avançada como um provável fator de risco pra a Covid-19.

Ao se analisar o gênero dos pacientes envolvidos nos casos da Covid-19, os resultados foram conflitantes. Observou-se um predomínio do sexo masculino em praticamente todos os outros trabalhos discutidos em diferentes países, China, França, Estados Unidos e Itália, e exceto neste trabalho e no estudo da Coréia do Sul, houve um predomínio do sexo feminino. Em valores absolutos, no presente estudo, houve 20 casos femininos e 16 casos masculinos suspeitos e estes não apresentaram significância estatística quando submetidos aos testes. Infere-se que possivelmente o tamanho da amostra possa ter influenciado em um resultado não representativo e que outros estudos e análises no Brasil devam ser necessários para definir o sexo como um possível fator de risco para a infecção contra a Covid-19 (WANG R, et al., 2021).

Diante da diversidade de sintomas que este enfermo pode trazer ao ser humano associado ao desconhecimento do quadro clínico completo e as diferentes variantes do vírus, torna-se essencial e, ao mesmo tempo desafiador, analisar e comparar os sintomas mais prevalentes encontrados. No presente estudo, dentre os pacientes que tiveram PCR positivo para Covid-19, observou-se a dispneia como o sintoma mais prevalente entre os demais, seguido de coriza, dor de garganta, tosse, cefaleia, febre e mialgia. Porém na literatura, nenhum dos demais estudos analisados apresentaram a dispneia como sintoma mais prevalente. Este esteve entre o segundo e terceiro sintoma mais prevalente nos demais estudos, possivelmente relacionado ao quadro de hipóxia "silenciosa" observado em alguns casos (VALERI AM, et al., 2021).

Estudos realizados em Paris, Itália, Estados Unidos da América e na Espanha apresentaram a febre como sintoma mais prevalente, correspondendo a 79.5\%, 68\%, 49\%, 77\% respectivamente (TORTONESE S, et al., 2020). Já no Hospital da Universidade Nacional de Kyungpook, na Coréia do Sul a tosse foi o sintoma mais 
prevalente $(50 \%)$, seguido pela dispneia (35.7\%) e fadiga (28.6\%). E estudo feito em Wuhan demonstrou outra divergência, sendo a fadiga como sintoma mais predominante entre os dialíticos. Ressalta-se que, apesar da predominância entre alguns sintomas, observa-se que muitos possuíam vários sintomas concomitantes, que se desenvolveram durante o transcorrer do enf ermo, sendo os principais identificados os supracitados (JUNG HY, et al., 2021).

Corroborando com os dados encontrados em todos os outros estudos analisados e citados nesta discussão, observou-se a Hipertensão Arterial Sistêmica (HAS) como a principal comorbidade encontrada nos pacientes da amostra, chegando a estar presente em $72,2 \%$ da amostra. Em estudos realizados na Columbia University Irving Medical Center, nos Estados Unidos, o percentual de acometimento chegou a estar presente em 98\% dos pacientes e na região de Bicetre, em Paris, esteve presente em 97,7\% (VALERI AM, et al., 2021).

A segunda comorbidade mais encontrada foi a diabetes mellitus do tipo 2, chegando a $47.2 \%$ dos casos no atual estudo, 69\% nos Estados Unidos 43\% em Paris, 50\% na Coréia do Sul (BAYER F, et al., 2021). Tal dado nos leva a considerar a possibilidade de estas serem apontadas como fatores de risco para a inf ecção, porém sua grande prevalência nesse grupo de pacientes e sua íntima relação com a doença renal terminal talvez dificulte essa análise. Outras comorbidades, como a obesidade, que recebeu um novo destaque durante a pandemia, também foi encontrada em $54 \%$ dos casos no estudo americano e em $34.1 \%$ no estudo francês citado anteriormente (YIQIONG MA, et al., 2019). Não houve a coleta deste dado nesta análise, assim como os demais estudos discutidos, os quais também não incluíram a análise antropométrica dentre as comorbidades analisadas.

Apesar da opacidade em vidro fosco possuir diversas outras causas não relacionadas a Covid-19, este foi um parâmetro de alta sugestividade associado ao quadro clínico para o diagnóstico da doença durante a pandemia. Sendo também utilizado no auxílio sobre decisão de internação hospitalar (de acordo com o percentual de acometimento), escolha quanto a antibioticoterapia e provável prognóstico do quadro. $\mathrm{Na}$ análise desta pesquisa mais da metade dos pacientes $(61.1 \%)$ apresentaram padrão radiológico com presença de vidro fosco, enquanto que $38.9 \%$ não demonstraram alterações na tomografia. Tais dados são concordantes com aqueles encontrados em Wuhan, Estados Unidos, Itália, Paris, Coréia do Sul e Madrid onde o percentual de vidro fosco encontrado nos pacientes foi de $59 \%, 59 \%, 70 \%, 80.5 \%, 71.4 \%$ e 775 respectivamente. Dessa forma, observa-se que o grupo de pacientes renais crônicos mantém o alto nível de comprometimento pulmonar encontrado também na população geral (DE LA FLOR MERINO JC, et al., 2021).

Um dos grandes desafios que envolvem a Covid-19 está relacionado aos desfechos imprevisíveis que o vírus pode ocasionar em diferentes organismos. Até o presente momento, segundo dados da OMS, já houve 4,9 milhões de mortes pela doença na população geral e diferentemente do que já se conhecia como fatores de risco para mal prognóstico, pouco se tem estabelecido sobre o quanto destes realmente influenciarão no desfecho final do quadro (WORLD HEALTH ORGANIZATION, 2021).

Fato observado nesta análise é que quase metade, cerca de $43,5 \%$, necessitou de internação hospitalar durante o tratamento, enquanto que, cerca de $1 / 3$, (30.4\%) realizaram tratamento ambulatorial. Da mesma forma, os estudos publicados na França, Itália e Espanha demonstraram que a maioria de seus pacientes necessitaram de internação hospitalar (48\%, 61\% e 66\% respectivamente), nos levando a inferir estes como uma população de risco para quadros mais graves da doença (TORTONESE S, et al., 2020). Já em um estudo publicado no Canadá, os dados foram conflitantes, demonstrando que cerca de $77,3 \%$ dos pacientes fizeram tratamento ambulatorial e só $22,7 \%$ necessitaram de terapia intra-hospitalar (YAU K, et al., 2021).

Quanto aos casos de óbitos nos pacientes dialíticos, seis evoluíram a óbito $(26,1 \%)$ neste estudo. Dados percentuais aproximados foram encontrados na região metropolitana da França, 19\%, na região de Brécia, na Itália, 29\%, e em Wuhan na China, 16\% (BAYER F, et al., 2021). Já na Coréia do Sul o valor percentual encontrado foi ainda menor, de apenas 14,3\% (JUNG HY, et al., 2021).

Alguns estudos publicados discutidos neste texto, como a série de 9 casos da Covid-19 de pacientes espanhóis, e os 11 pacientes com a Covid-19 do estudo em Toronto, no Canadá, não apresentaram casos de óbito até o momento da pesquisa ser divulgada, possivelmente devido se tratar de amostras pequenas e 
que tenham sido analisadas durante um curto período de tempo e que não necessariamente tenham o mesmo resultado após maior tempo de seguimento (DE LA FLOR MERINO JC, et al., 2021).

\section{CONCLUSÃO}

Houve uma prevalência de $20(58,8 \%)$ casos da Covid-19 no grupo estudado. A faixa etária mais acometida do grupo foi entre 70 e 79 anos demonstrando a idade avançada como um possível fator de risco para a doença. O gênero feminino foi mais acometido neste grupo. Dentre os sintomas, a dispneia foi o predominante nos pacientes positivos para a infecção. A hipertensão arterial sistêmica foi a comorbidade mais prevalente, em 26 pacientes, podendo representar potencial um fator de risco para a infecção pelo SARSCoV-2. O acometimento pulmonar foi uma das principais características observadas na maioria dos pacientes. Supostamente seus níveis de acometimento representam fatores prognósticos quanto ao desfecho clínico. Há uma grande necessidade de tratamento intra-hospitalar nesse grupo de pacientes reforçando sua susceptibilidade a quadros mais graves do enfermo.

\section{REFERÊNCIAS}

1. ALBERICI F, et al. A report from the Brescia Renal COVID Task Force on the clinical characteristics and short-term outcome of hemodialysis patients with SARS-CoV-2 infection. Elsevier Public Health Emergency Collection, 2020; 98(1): 20-26.

2. BASILE C, et al. Recommendations for the prevention, mitigation and containment of the emerging SARS-CoV-2 (COVID-19) pandemic in haem odialysis centres. Nephrol Dial Transplant, 2020.1;35(5):737-741.

3. BAYER F, et al. Low incidence of SARS-CoV-2, risk factors of mortality and the course of illness in the French national cohort of dialysis patients. National Library of Medcine, 2021. 98 (6):1519-1529.

4. DE LA FLOR MERINO JC, et al. COVID-19 in chronic hemodialysis patients: A report of 9 cases in Madrid, Spain. National Library of Medcine, 2021.95: 45-53

5. FEHR AR, PERLMAN S. Coronaviruses: an overview of their replication and pathogenesis. Methods Mol Biol, 2015.1282:1-23.

6. INAH MARIA D, et al. COVID-19 e doença renal crônica: uma revisão abrangente. Braz. Jornal brasileiro de Nefrologia, 2021.43(3):383-399.

7. JUNG HY, et al. Outcomes of COVID-19 among Patients on In-Center Hemodialysis: An Experience from the Epicenter in South Korea. National Library of Medcine, 2020.9(6):1688.

8. MCINTOSH K. COVID-19: Epidemiology, virology, and prevention, 2020. Disponível em: https://www.uptodate.com/contents/covid-19-epidemiology-virology-and-prevention. Acesso em 20 de Outubro de 2021.

9. MINISTÉRIO DASAÚDE. Protocolo de Manejo Clínico para o Novo Coronavírus (2019-nCoV). $1^{\text {a }}$ edição 31 p. Brasilia - DF: $\quad$ Brasil, $2020 . \quad$ Disponível em: https://portal.fiocruz.br/sites/portal.fiocruz.br/files/documentos/protocolo_manejo_coronavirus_ms.pdf. Acesso em: 18 de Agosto de 2021.

10. NAICKER S, et al. The Novel Coronavirus 2019 epidemic and kidneys. Kidney International $(2020) 97,824-828,2020$.

11. ROMBOLA G, et al. Indicações práticas para a prevenção e gestão de SARS-CoV-2 em pacientes em diálise ambulatorial: lições da primeịra fase da epidemia na Lombardia. Open Journal of Nephrology, 2020;33:193-196.

12. SECRETARIA DE SAÚDE PÚBLICA. Plano de contingência estadual para a resposta à emergência de saúde pública - Covid-19 - 4a edição 49p. Belém - PA: Brasil, 2021. Disponível em: http://www.saude.pa.gov.br/wpcontent/uploads/2021/08/COE-Plano_de_Contingencia_Estadual_Oficial_4edicao-REV.pdf. Acesso em 02 de Outubro de 2021.

13. SOCIEDADE BRASILEIRA DE NEFROLOGIA. Recomendações de Boas Práticas da Sociedade Brasileira de Nefrologia às Unidades de Diálise em relação a Epidemia do novo Coronavírus (COVID-19). 6p. São Paulo - SP, 2020. Disponível em: https://www.sbn.org.br/fileadmin/user_upload/sbn/2020/07/15/COVID19_SBN_Atualizada_17-3_pdf. Acesso em 02 de Outubro de 2021.

14. TORTONESE S, et al. COVID-19 in Patients on Maintenance Dialysis in the Paris Region. Kidney International Reports, 2020.5, 1535-1544.

15. VALERI AM, et al. Presentation and Outcomes of Patients with ESKD and COVID-19. Jornal da Sociedade Americana de Nefrologia, 2021.31 (7), 1409-1415.

16. WANG R, et al. COVID-19 in Hemodialysis Patients: A Report of 5 Cases. American Journal of Kidney Diseases, $2021.76(1), 141-143$.

17. WORLD HEALTH ORGANIZATION. Severe acute respiratory syndrome (SARS), 2003. 4p. Disponível em: https://cdn.who.int/media/docs/default-source/documents/health-topics/mers/wha56-29-agenda-item-14-16sars.pdf?sfvrsn=16254555_8. Acesso em 07 de Outubro de 2021.

18. WORLD HEALTH ORGANIZATION. Coronavirus Disease (COVID-19), 2020. Disponível em: https://www.who.int/health-topics/coronavirus\#tab=tab_1. Acesso em 01 de Dezembro de 2020.

19. YAU K, et al. COVID-19 Outbreak in an Urban Hemodialysis Unit. National Library of Medicine, 2021. 76(5): 690-695.

20. YIQIONG MA, et al. 2019 novel coronavirus disease in hemodialysis (HD) patients: Report from one HD center in Wuhan, China. Biblioteca virtual em saúde, 2021.

21. ZHU N. et al. A novel coronavirus from patients with pneumonia in China, 2019. The New England Journal of Medicine, 2020.382:727-733. 